\title{
AiMT
}

Advances in Military Technology

Vol. 15, No. 1, 2020, pp. 7-24

ISSN 1802-2308, eISSN 2533-4123

DOI 10.3849/aimt.01332

\section{Robot as a Member of Combat Unit A Utopia or Reality for Ground Forces?}

\author{
J. Matejka* \\ Unmanned Solutions, Inc., Nové Mesto nad Váhom, Slovak Republic
}

The manuscript was received on 10 May 2019 and was accepted after revision for publication as technical information on 8 December 2019.

\begin{abstract}
:
There is a perceptible scepticism around armed robot in combat units - the question whether to use it or not. The EOD robots (EOD - Explosive Ordnance Disposal) won their way to war theatre already, but other support assets on UGV platforms (UGVUnmanned Ground Vehicles) need to be trusted in future, too. One of the reasons for distrust could be a discussion gap between researchers and infantry units on the lowest tactical level. The article tries to set simple demands throughout infantryman-eyes perspective and it outlines needs for the UGV in the mechanized/infantry units in a first part. The second part outlines basic technical and tactical specification as a challenging list for development teams. Finally, the third part proposes two notional AAR (After Action Report) reports of units using UGV for support. The article sets basic questions of themes as the autonomy and controls of UGVs and UGV in ISTAR systems (ISTAR Intelligence Surveillance Target Acquisition Reconnaissance).
\end{abstract}

\section{Keywords:}

after action report, armed $U G V$, autonomy of $U G V$, controls of $U G V$, force multiplier, mechanized infantry, restricted terrain $U G V$, urban operation

\section{Introduction}

If we look around recent military projects' agenda worldwide, we shall find out a pretty large number of research centres of the biggest armies using considerable budgets for development of Unmanned Ground Vehicles - UGVs, even those of the greatest interest for this article - armed UGVs. But the reality here in Europe is slightly different and the cooperation between armed forces and research centres is still not adequate. Let's take a look on this issue from a slightly different angle, from an infantry point of view. As a former mechanized infantry officer, who also served for few years in training facility for tactical-level units, I will try to answer few presented questions about this situation.

\footnotetext{
* Corresponding author: Unmanned Solutions, Inc., Nové Mesto nad Váhom, Slovak Republic, Phone: +42190594 52 44, E-mail: jaroslav.matejka@centrum.sk
} 


\section{Force Multiplier, not a Soldier Replacement}

A challenging task of armed unmanned vehicles as a kind of force multiplier for combat units started to vibrate more and more often throughout the conferences, institutes and development companies' portfolios even in European business space in recent times [1]. Interconnection between them and the military is still not perfect, mainly in the tactical-level structures. The army institutions and main army bodies are often quite slow-minded in introducing new technologies; units' commanders simply did not trust them from the start. This task waits for a push-up, but this speed-up of technology pace has always been connected to the war or war crisis era; the history is unfortunately full of examples. In the army community, there are even some worries that robots could replace the infantry in future. But this idea is wrong and no one really could do this, certainly not for a long time. The Infantry - the Queen of the battlefield and its strategic area dominancy, well formulated by the verbalism Boots on the Ground, has an irreplaceable role in restoration or establishment over strategic and tactical supremacy of given space. And that is true; the vision about replacement of a soldier in field with a robot is false for now and it represents misapprehension of vast opportunities given by robotic platforms as multipliers of not-far future. Still, the Foot of the Infantryman will dominate on the battlefield for a long time; but it could have significant helpers - the UGV and UAV (Unmanned Aerial Vehicle) platforms with adequate sensor outfit, support armament and protection would be very useful. Both land and air unmanned platforms will cooperate in next wars, the swarming effect concepts of these platforms and MUM-T (Manned - Unmanned Teaming) procedures are being already conscientiously evaluated. All these projects are intended to help the combat units, not to replace them totally. An effect of multiplier tool is needed on the battlefield. To start with, we need to focus on small units and their tactics and that is the issue of this article. Armed UGVs and UAVs may even represent a partial solution for today's demographic situation in European army bodies, where human-resource numbers are dropping down hand in hand with more and more expensive costs and time consumption of training tasks per person. "Robot fulfil the task, but only human fulfil the mission." - LCL Rémy Hémez [2].

As long as we want to describe the UGV assets shortly and simple-tongued, we shall start with a set of statements that these unthinking machines are from the very nature of construction more resistant against damage than our human body (with appropriate design, of course), they react faster with adequate software kit and do not know fatigue. If the batteries or fuel tanks have an adequate stamina, they will hold on the same operational level as any other human unit at the endurance-time period around 24 hours. We could even use a statement quite well-known in UAV operators' community: "Try to not blink with your eye for 36 hours..." [3] The concept D3 (Dirty-Dull-Dangerous) is generally mentioned for UGV tasks and it outlines aptly advantages. They are ready for heavy lifting or transport tasks - monotonous patrols and marches - dangerous objects and areas search - and exhausting fight. Generally the overall dimensions of UGVs are more compact than other manned battle-support platforms; and what could be even more important - UGVs are relatively cheaper than many complex weapon systems... and of course human. The finger on the trigger, eye on sights does not shake them under the fire; the optronics systems are multiplicatively accurate, reaction times and pre-programmed analytic capacities could be multiple times faster than our human ones. Speed and accuracy means survival on today's battlefield, the future wars will need this even more. The accuracy of proposed high- 
precision sniper robots for instance [4], could be far beyond skills of humans, and this acquisition would credit every commander in future field as a brand-new battle feature. Let's not forget that many naval platforms could not imagine the air defence without automated and fully autonomous systems nowadays; many critical intelligence data would be lost without today's unmanned aerial systems.

On the other hand, these days or in the near future, we are probably not able to build a computer system capable of copying our complex sensory perception, decisionmaking abilities of a human - trained member of armed forces; the empathy, even the sense of honour or quilt are still in purely human nature. But the UGVs could still fulfil the role of a units" "wingman" with semi-autonomous pre-programmed characteristics quite well [5]. The brain of the activity will be a nearby trooper - member of a unit, who will determine to our robot what the task is and afterwards just supervise, he could metaphorically forget this wingman. Its duty will be semi - autonomous. The expression Man in the loop - man behind the trigger, needs to have practically more and more loose meaning for the future. A firm doctrine needs to be evaluated and built by all armies who want to participate; the global technology development shows us that it will be compulsory. These lines may help with it.

“Autonomy is a political decision." - LCL Rémy Hémez [2].

\section{Design of UGV versus Infantryman}

Small unit tactics and troopers need a backup multiplier and a "wingman" on the lowest level of command. In the next lines, we will focus only on these concepts, the use of UGV as a force multiplier and a helping device in sections and platoons. At the beginning of the previous chapter, we hinted a not quite perfect interaction between designers and members of combat units. Of course, honour the exceptions... But many developing studies and projects start in the following order (Fig. 1).

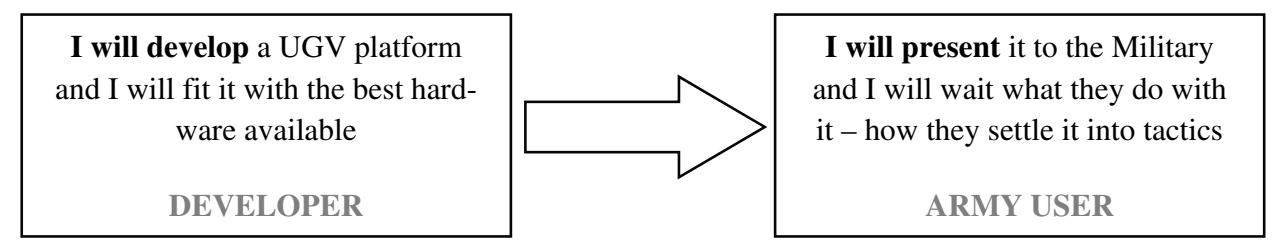

Fig. 1 Developer and army user relations

Developers equip their UGVs often with the best contemporary state-of-the-art gadgets of reconnaissance, intelligence, data gathering and satellite navigation, etc.; but do we always need all these toys for real? Let's turn the pattern over in our paper and try it this way (Fig. 2).

\begin{tabular}{|c|}
$\begin{array}{c}\text { I will analyse what kind of sup- } \\
\text { port UGV my infantry unit needs } \\
\text { for real } \\
\text { ARMY USER }\end{array}$ \\
$\begin{array}{c}\text { I will develop UGV with best } \\
\text { design and effectiveness to be } \\
\text { leverage for the unit }\end{array}$ \\
DEVELOPER
\end{tabular}

Fig. 2 Army user and developer relations 
Just imagine that now you are a member of mechanized infantry section equipped with IFV (Infantry Fighting Vehicle) - a rifleman with an assault rifle, and you would answer for yourself these questions:

- Do I really need an armed unmanned ground vehicle for support?

- Could this be a real help for my unit; if yes, how?

We could try to answer it by these three schematic situations after the contact with the adversary, of course in a very simplified way. First one is in a simple open grounded area (Fig. 3).

1. SYMMETRIC
BATTLESPACE
OPEN GROUND

\section{Fig. 3 Open ground situation}

The combat support may seem sufficient for our unit here. But after the first contact with an enemy, the direct fire support takes lead. It is an ultimate effort to win the firepower superiority - to out-gun the enemy, where any powerful weapon is irreplaceable; IFVs or MBTs (Main Battle Tank) are troopers' best friends... What to do next in the situation where mountainous or densely forested terrain covers all our operation area (Fig. 4)?

2. SYMMETRIC
BATTLESPACE
RESTRICTED TERRAIN

\section{Fig. 4 Restricted terrain situation}

Again, more information means a good overall awareness, but after the first contact with adversaries, we need the main - firepower and ammunition. From this point of a story, it started to be interesting for an infantry trooper, too. The last but not least for today's battlefield is an urban operation - built-up area, which is for a commander 
the most $3 D$ command-space to imagine; unfortunately, the most frequent of future battles, where any integral support of the unit is crucial (Fig. 5).

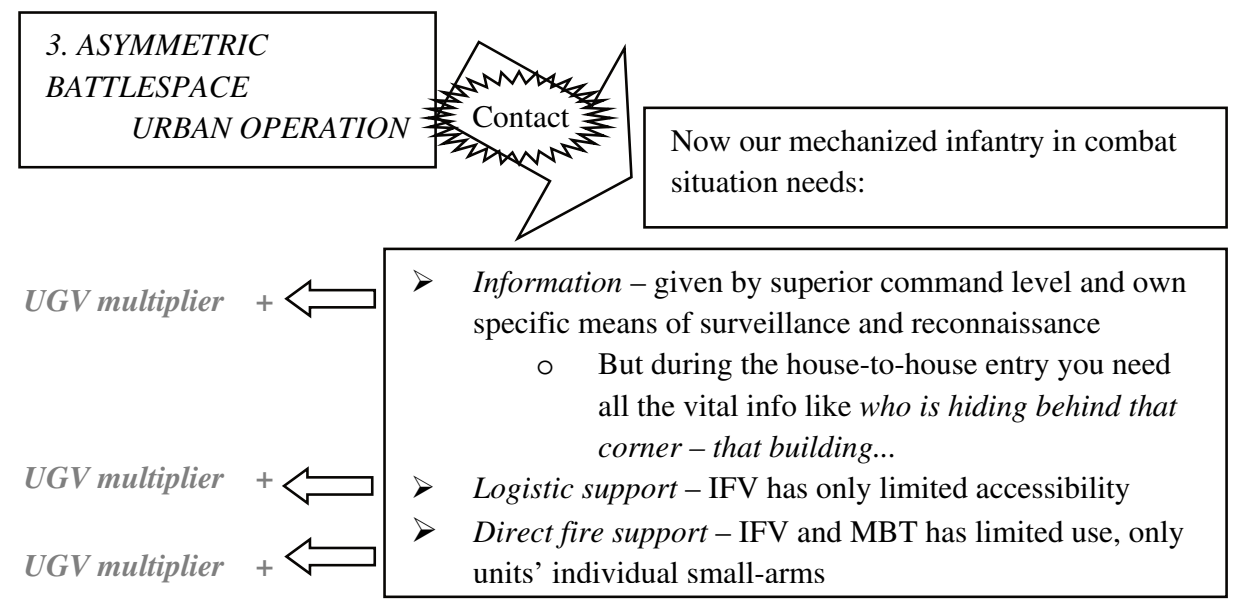

Fig. 5 Urban operation situation

Information - to gain information, observation, target acquisition and general survey over the battle-space, often hidden in well-known acronym ISTAR (Intelligence Surveillance Target Acquisition Reconnaissance), could be a necessary tool for special unmanned ground platforms; for mechanized or infantry units on the tactical level decision-making has no greater value. This capacity is a domain of reconnaissance and special units, either in integral unit's formation or of a superior command level. The mission and tasks of these units are but different, they do not win the supremacy in operation area and as we mentioned at the beginning that is the infantryman, who wins another day... Result: NO, not crucial.

For units in direct contact with the enemy is therefore predominance in firepower crucial, hand in hand with an ability to take and withhold an area with own supplies of ammunition, supplies, water or medicals. A platform capable of that (a Mother-Ship concept), to support a unit during the fight, must be autonomous sufficiently enough, not to interfere with standard combat duties of the rifleman - operator [6].

Direct fire support is therefore for the infantry most necessary without any compromise. Not to count the indirect fire support, as artillery, airstrikes etc., unit counts for its integral weaponry as an IFV or assigned means as a MBT. But our previous two schematic situations show us these supports with really limited capabilities; our unit may lose it in rugged restricted terrain and in the narrow urban areas. Now, we are getting the point. As long as the UGV platform may help mechanized infantry unit to take supremacy and withhold the area, it needs to be weaponized and well-armed. Result: YES, crucial (Fig. 6).

A note to mention, there are even attempts to support MBTs during the combat with their own "wingman" - heavily armed and protected tank-like platforms [7, 8], which could dramatically change the symmetric armed conflict on open ground theatre. That is but a different story, meaning that infantry would be assisted by diverse means in the future. 


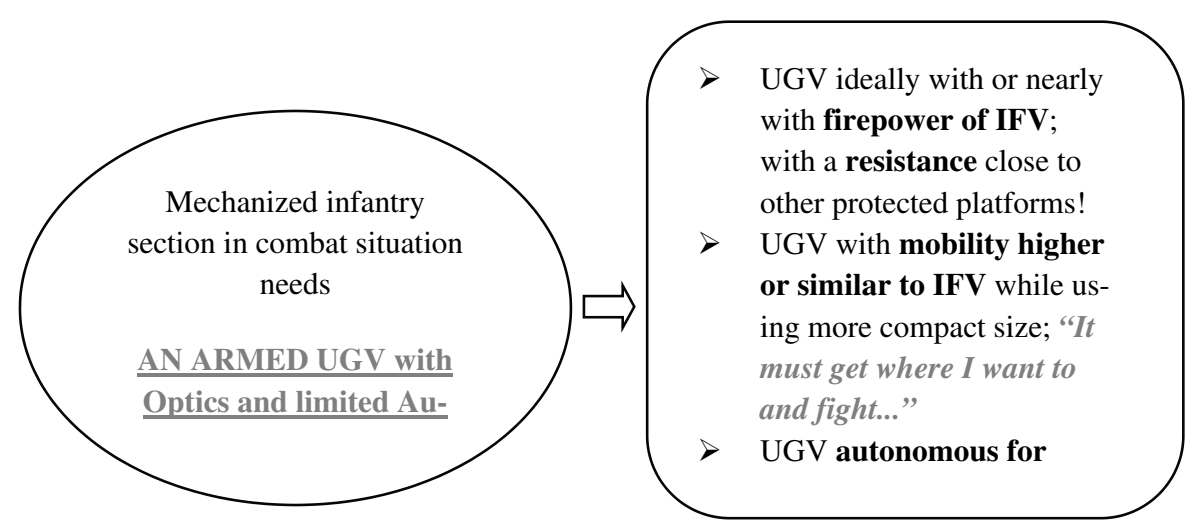

Fig. $6 U G V$ as a direct fire support for infantry

Direct logistic support of mechanized infantry section or whole platoon is dependent on the ability to carry supplies with it; only what I can carry can help me, this truth was many times proved by units during operations in mountainous terrain and mainly during the urban operations, where the complexity and opacity of situations often led to the cut-off of whole companies from supply convoys.

And again, if UGV platform may help, it needs to be able to transport large cargo without the rifleman - operator forced intervention. Result: YES, usable (Fig. 7).

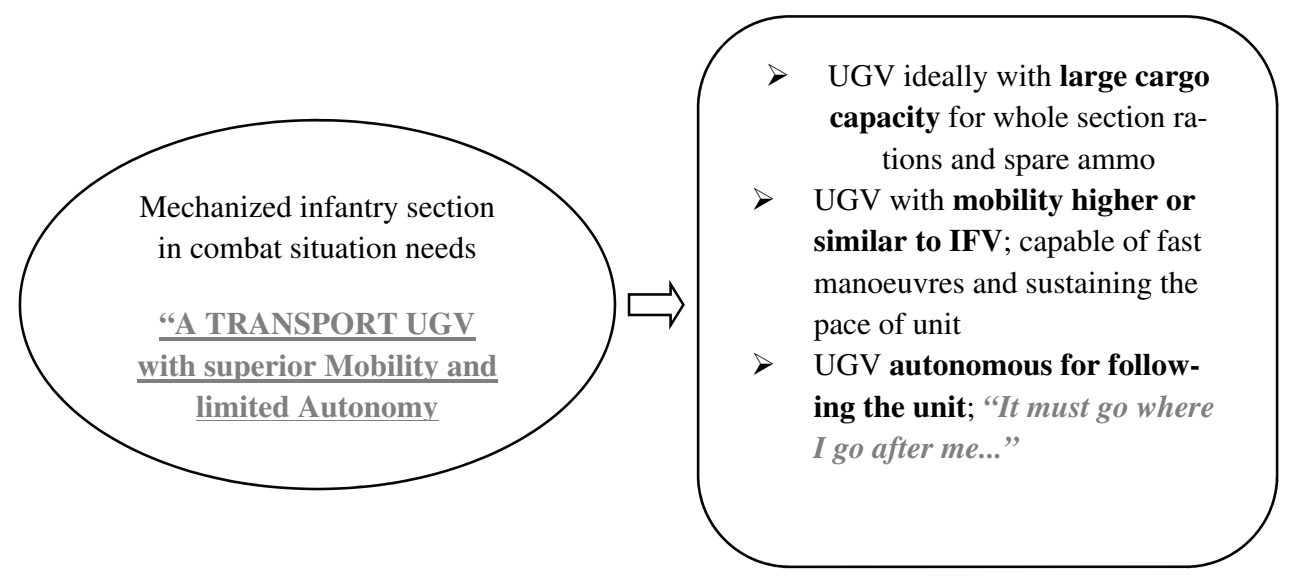

Fig. 7 UGV as a direct logistic support for infantry

These theoretically answered questions as a rifleman set basis whether or not a unit needs unmanned ground platform and if yes, how effective it could be. But is it possible to combine these frequently conflicting requirements and if yes, which type of chassis to use for movement?

For example, the logistic application of an UGV platform according to the outlined requirements would prefer wheeled chassis, mainly because of faster manoeuvre, lower noise level and simplicity at the expense of worse ground mobility and resistance. 
On the other hand, armed application needs a platform which is more stable and more resistant, sturdy, which gives you tracked chassis with higher obstacles mobility, at the expense of noisiness and complexity of the chassis.

To complete today's trends in research, we have to mention also projects of legged chassis robots, which are intensely under development in army research centres. Work is heading forward rapidly, but it is still a long way to go to customize it for dirty and crude infantry role. This type of chassis has a complicated chassis with many moving parts, stability is still not sufficient, the rate of carried cargo low and even the noise level during movement is considerable. However, the ground mobility would be outstanding after overcoming the "childhood" difficulties and it could even outperform both previous mentioned types in the future.

Other kinds of movements as crawling and creeping (snake-like robots) are being studied too, but most of these chassis and movements would be suitable for reconnaissance tasks due to slow and hardly noticeable movement predetermined for small UGVs. This movement principle is not suitable for large UGVs.

Due to nowadays condition of research, the wheeled and tracked chassis are the most appropriate and we will focus on them. To combine opposing requirements into one system for general combat support of a fighting unit would be possible only at the cost of compromises; or to go through an independent way of development for each support need... Let us try to outline some basic technical and tactical specifications of UGV platforms as our main aim of infantry interest and let us present them to potential designers as a challenge.

\section{UGV for Combat Support of Small Unit}

If we focus on the unmanned vehicle as a firepower and support force multiplier for small tactical-level unit of ground forces - a mechanized infantry section equipped by tracked or wheeled IFV - we could set these three basic questions and answers about ideal patterns of UGV in a designer fashion - technical parameters on the first place, requirements for sufficient armament on the second one and at the end those military most valuable - tactical characteristics.

What basic TECHNICAL PARAMETERS should UGV have for the support of the mission with a mechanized infantry section? We assume that one UGV will be integrated into a section as a support element or as an individual fire team:

- compact dimensions - an important feature, creating problems for designers from the beginning, however crucial for more reasons. Firstly, low visual, radar and IR signature (IR - Infra Red), low and compact profile is better suited to camouflage; secondly irreplaceable during urban operations in built-up areas, where an ability to enter doors of buildings without previous demolition is useful. Small size could be helpful to store it or to transit more vehicles during air-transport and airdrop operations,

- $\quad$ speed and ground mobility - it is directly defined by dismounted infantry unit pace. Set speed for infantry is $3-4 \mathrm{~km} / \mathrm{h}$ for daytime, $2-3 \mathrm{~km} / \mathrm{h}$ during night. The platform must be able to withstand and sustain the pace with unit also in moderately difficult restricted terrain, mild-climate forests, sandy surfaces and of course during the urban combat. UGV must be able to generate even faster velocity for necessary manoeuvre, optimal route searching, or avoiding obstacles. Some of combat manoeuvres in complex terrain need short-term higher speed, where a dismounted soldier's jog is around 7-9 $\mathrm{km} / \mathrm{h}$; hence we 
could expect for our UGV a higher operational speed of $10-15 \mathrm{~km} / \mathrm{h}$ for sustaining operational pace,

- batteries capacity (for a hybrid drive combustion engine fuel supply) - is a key element together with sustaining the operational pace. It is one of the most difficult tasks for the designer. Most of today's systems with electrical drive are able to perform in the order of hours - 5-12 hours; it depends on tasks and operational pace. But units fight independently in the order of days... Therefore the endurance of $24+$ hours appears to be a minimum for platform ready for patrol duties or other less-energy consuming operation, logically reduced during high-energy combat tasks. Integrated sleep mode for batteries and systems during breaks is essential. Spare batteries could be reloaded in IFV, if available, but light infantry units or situations where it is not possible to deploy IFVs will need the capacity as large as possible. The battery capacity or endurance of the platform depends also on version and level of equipment of UGV, e.g. an add-on armour protection during CQB (Close Quarter Battle) ops will decrease it, lighter version for patrol and reconnaissance will increase it proportionally,

- obstacles and staircase climbing - not an important feature at first look, but in real combat contact with adversaries again crucial. Overcoming doors in buildings (where a width is often less than $90 \mathrm{~cm}$ !) and clearing rooms is an ultimate task of units during MOUT (Military Operation on Urbanized Terrain) operations and directly during $\mathrm{CQB}$ fighting. Although this feature is in contradiction to some other possible parameters of the UGV, we need to mention it. Today's battle-space offers urban tasks and armed conflicts in urban areas more frequently and their intensity will unfortunately rise; none of the unit will avoid that in the future [1]. The need to adapt UGVs for that will call for mentioned compact dimensions, low Centre of Gravity (remember that remote weapon stations will raise CG dramatically) and intentionally designed chassis. The tracked chassis plays the prime here,

- waterproof protection - overcoming the water surfaces by fording or floating is related firmly with operational manoeuvre in Middle European theatre. It is not a common requirement for combat systems nowadays; most of today's battlefields are located in dry climate, but this may be changed very rapidly in future. Infantry is often forced to overcome various watercourses, during which a fast fire-strike of a small and hard-to-hit UGV could be useful. Anyway, if not fully waterproof, the protection against spraying water and pools of rainwater has to be a minimum for each platform serving in the army,

- protection against small-arms fire - another difficult task for design departments; protection costs many compromises, armour protection is heavy, it is also quite bulky. The platform has to provide a minimum emergency cover for combatants around; of course its own protection of key systems is a basic. The possibility how to solve the issue is an optional protection kit, simply an adding of armour plates for front / sides of the hull based on commander's order or given tasks. The low intensity combat task - protection is disassembled, action radius and endurance are scaled-up, the high intensity fight (CQB ops) - reversely protection is higher at the expense of endurance. The protection level STANAG 4569 Level 1 could be reached for example by using soft-armour ballistic fabrics combined with hard plates and by structure 
design itself [9]. Generally designers need to focus on key elements and energy-hubs safe placement of the platform, all important parts need to be located inside or backed up. This protection depends significantly on the overall concept of given platform and ratio cost against benefits outlined by this concept,

- protection against WMD - the threat of WMD (Weapon of Mass Destruction) use started to be increasingly mentioned worldwide, so it is worth mentioning it, too. Machines are principally more resistant against chemical, biological or radioactive agents. But many modern artificial materials and mainly the electronics are not. Some alloys and plastics are corrosively sensitive for chemicals; electronics is vulnerable against EMP (Electro Magnetic Pulse) and radiation. And your platform needs to withstand decontamination with anti-WMD agents on the other hand. Therefore the designer has to count on it from the very beginning, if the platform is intended to withstand it. This protection as a benefit is a matter of overall costs for platform again dictated by the concept,

- user - friendliness and versatility - under this commercially looking title, various soldier-friendly gadgets as impact protective frames and handles, usable also during carrying or loading process are hidden; even a wounded soldier under fire could be towed into safety using these handles by UGV. Hence a feature of towing a load for around $120-150 \mathrm{~kg}$ should be a matter of course. Optional transport basket attachment, stretchers attachments or fast replacement clips for support-weapon manual mount will help the unit to customize its platform for given tasks and to use better ration, water and supply management. And since we need to train and fight during nights, some efficient spotlights and sidelights would be for safe work vital too,

- field service - following the previous part, chance of field maintenance, repairs and mainly adaptations of UGV platform without using special tools will be necessary. The mentioned concept D3-EC (Dirty-Dull-DangerousExtra Cheap) should be applied where it is possible and necessary. The EC of concept is useful, but it must not interfere with military grade of quality. The batteries replacement, damaged or destroyed parts exchange, dismantling of sub-assemblies for transport in field will make it easier to handle many unpredictable situations. The improvisation is a mother of soldier...

What sufficient ARMAMENT AND FIREPOWER should UGV have as a valuable firepower force-multiplier of small tactical unit? We will count on the fact that optronics sensors of our UGV are efficient and more accurate than our eyes; therefore, we need a really efficient weapon system matching it with performance:

- remote weapon station and optronics - the basic compact mount and gun sights have to be designed in a manner to use section's integral support weapons as $7.62 \mathrm{~mm}$ general purpose machine gun or grenade-launcher, not specialized heavy-support weaponry out of the sections inventory. Logistic and technical advantage is obvious; we must not forget logistic ammunitionsupply chain and bear in mind that the event of destroying the platform will cost us only the chassis and optronics itself; weapon could be simply unmounted and used subsequently in section's formation. Another important benefit is a higher ammunition supply rate in hand of a unit - a feature allowing to out-gun the adversary. 
- heavy weapons - $12.7 \mathrm{~mm}(.50 \mathrm{cal}$ ) weapon (and more) or ATGW - if the situation needs an overwhelming firepower and weaponry for engaging armoured targets or fortifications (to be honest, almost ever...), this possibility exists $[10,11]$. ATGWs (Anti-Tank Guided Weapon) of 3rd Generation or higher are generally available. The limitation lies in weight, since heavier weapons need more robust platforms and the overall weight of the vehicle will be considerably higher, too. Logistics comes into play again, unit needs supplies of weighty extra-ammunition; destroying of the platform leads to failure of the whole support-fire system. But all these negatives are balanced by unprecedented firepower of infantry unit discussed in the previous chapter - the firepower is nearly equal to IFV weaponry,

- stabilization of the weapon station both in elevation and azimuth - it is today, in the era of miniaturized electronics, almost compulsory; some of the stabilized RWS (Remote Weapon Stations) weigh even around $30 \mathrm{~kg}$ [12]. Sensors will be less strained on the stabilized platform than without it; for this situation, a tracked chassis is again more suitable. The negatives are rapid rise of price for the weapon station and complexity with higher chance for errors. But many companies offer wide portfolio of RWSs for different platforms and it seems that this technology is well managed already,

- smoke grenade launcher - the ability to screen-out our formation and to cover it is as old as warfare itself. This feature plays a great role in modern conflicts too, where using high-performance multispectral smoke screens is only the basics; we have a wide portfolio of special purpose grenades as antipersonnel, tear-gas, non-lethal ones, etc. And when a platform will have sensoric and software equipment for an automatic, active-defence response for threats, this could certainly save lives in units. The rise of weight is again our limitation for small and medium sized platforms.

What basic TACTICAL CHARACTERISTICS do we need finally to get ready the UGV platform for fight and not to make another useless piece of machinery for the mechanized infantry section? After the technical parameters and armament were put on the list, we need to join it together with really good tactical attributes. Let us start with a weirdest one for designers maybe, but crucial for real deployment:

- transportability - by the organic vehicle of the unit, a very basic question for the commander, how to get this thing into the frontline? The unit uses either a wheeled or tracked IFV (remind the Mother-ship concept). This tactical deployment of the UGV is often neglected by designers. The operational space even in its own territory could be vast and fast manoeuvres are impossible to execute using UGVs own axis. Their speed and endurance are still very limited. It is often solved by a truck transport, but does our platoon or companysize unit has a spare truck for it? - A driver for the truck? - A parking place back on the home base? - Does this truck withstand the same as IFV, is it fast enough for the pace through rough terrain? ... Etc. No, to be a true helper, the UGV must go somehow with the unit! The design department has more options how to fulfil it - to transport it inside the mother vehicle, on top of it (or side / back?) or to tow it on some customized trailer. First possibility - broadly used by EOD teams and their UGVs - is for mechanized infantry and its inner cramped space of vehicles useless and it needs to be solved differently. Transport on the body of IFV itself in some protective container (with auto- 
matic or semi-automatic release function and activation, for instance), alternatively attached by some quick-lock clamps for easy and fast manual activation, is doable only by small sized UGVs. The construction limit is the size and weight of UGV platform. Other possibility is a combined transport, when a chassis of the platform travels on the body of the IFV and weapon with optronics inside it, if the inner space allows it, ready for manual attachment and activation. This combined solution could lower the inner volume occupancy on acceptable level. Third one, an attached single-axle trailer specially utilized for UGV looks as impractical solution for infantry fighting vehicles because of the troops' back ramp or door, but actually a very simple gadget to think about (there are already some modern designs of logistic trailers for heavy armour use, just to be inspired by it) [13]. Transportation and deployment features are related with a necessary semi-autonomous or even autonomous activation system of the UGV in matter of seconds - the reason is obvious - vulnerability of the IFV and troops during un-mounting activity in the middle of combat situation,

- ISR (ISTAR) - we partly noted these features in the previous chapter and yes, some of them are not always needed for the infantry. But it is without any doubt that today's almost-digital battlefield needs information; for our purpose certainly in some Spartan and bulletproof fashion. ISR or ISTAR, the question is whether the mechanized platoon will use a function of TA (Target Acquisition) or it is more suitable for reconnaissance units; but let it be there. Step by step, what these letters could mean for our platform:

1. intelligence - collecting the data and information. Platform needs to be able to gather, to record and eventually to send real-time Intel. The recording capacity needs to match with our deployment overall endurance - mentioned 24+ hours as basics, and it is necessary for after-action evaluation. Standard waterproof connectors and interfaces are obvious here. And the data needs to be encrypted as standard too,

2. surveillance - observation capabilities. The range of all optic observation systems of the platform has to extend standard means of the infantry section individual equipment and of course our eyesight. In the case, that we use a complex terrain of the Middle Europe battlefield concept, it is virtually a bubble above the ground with $2.5 \mathrm{~km}$ and more in diameter, in daytime, night, in all weather conditions [6],

3. reconnaissance - active survey. Means of surveillance would be actively used by a commander in connection with ground mobility and stabilized weapon platform. A reconnaissance using UGV must push the limits in precision, quality and fastness how the data are collected. The UGV does not sleep, the sensors do not get tired, it is capable of gathering Intel unprecedently longer as a human patrol member, even in hazardous unsafe environment,

4. target acquisition - pointing out the targets. A term which includes wide repertory of activities, and as mentioned before, a feature important mostly for reconnaissance units, artillery FOs (Forward Observer), FAC (Forward Air Controller) services, or similar. UGV platform could bring a great benefit to it thanks to its small size, cover movement and other features described above. Still, the TA is not necessarily connected with direct support of our infantry unit. 
- identification IFF - Identification friend-foe was always difficult in critical situations and it the errors in it may lead to tragic incidents. Shooting blue on blue (means a fire onto own units or allies) is a nightmare for all commanders in the field. Unfortunately, most of small infantry units are nowadays still not equipped with the IFF (Identification Friend or Foe) systems ordinarily used by air force, navy or special units. The reasons are obvious; besides some additional weight, the main factor is the price. But the IFF must create an inseparable need of all armoured and unarmoured platforms in near future battlespace, later for individual combatants too. And after that, if all assets in battlespace will have own encrypted IFF systems, critical situations would be minimized. The danger of accidents may even drop down to a level lower as today, using the UGV platforms with proper analysing software,

- operation, controls and autonomy - this important part of our tactical abilities (it is intently not placed in technical parameters before) will be dealt with as the last one and we will dedicate it more space here.

To operate the system and its autonomy is an alpha-omega as a whole and it directly leads us into the problems of true direct-support of a combat unit - the platform needs to be a real support, not a burden for combatants. The control over the UGV platform would have commander of the unit, whether throughout designated operator or even by his own controls. But to control - to give orders to the UGV by a commander - it must not have a limiting effect of his main task - to command. Therefore, a better solution seems to be a role of rifleman - operator of $U G V$, who will carry out tasks in close cooperation with a commander - he should have only an emergency control panel in the case of injury or loss of UGV operator. This new team-member of the unit may have been chosen and trained directly from integral manpower or the new platforms will force to change the structure of units on tactical level; only field experiments or real operational deployment will show us the proper way. Even a possibility of remote deployment and teleoperation from afar similar to today's large aerial drones may come to agenda and the platforms will be assigned to units after receiving the operational task. But that is probably a far future, this choice is still limited by progress in control systems, encrypting and data transfer systems; and it is out of the scope of this article.

Now we shall go back into the mechanized infantry section/platoon formations and try to think how UGV could be controlled - operated directly in the battle. US Department of Defence (DoD) published some time ago a smart chart, which we still have to agree with, describing different levels of autonomy for unmanned systems (Tab. 1).

The chart shows us clearly, that Level 1 is for our purposes unusable. It would strongly limit the rifleman and the commander in combat. Level 2 is a basis from which we shall go further, but according to short characteristics in the chart, level 3 represents most of what we expect. Other very comprehensible and easy-to-remember sorting of autonomy is expressed by phrases: Man IN the loop - according to our chart Level 2, "Man ON the loop "- Level 3" and "Man OUT of the loop "- Level 4 $[15,16]$.

Controls: Now system is deployed in area of responsibility, a unit is in proper formation, all positions are taken, and we have a UGV ready for action; and we need controls... Multiple companies prefer PlayStation-console kind of controls (although militarized) because of their common knowledge around young population [17]. It has but one great disadvantage - it needs two hands - a significant handicap during con- 
tact with adversary. A kind of a rugged tablet or mobile phone device attached on the forearm or on the front panel of the vest would help well; the goal is to use only fingers of one hand. It gives you more freedom during tactical activities - an important feature needs to be an intuitive graphic interface and already mentioned semiautonomy of the $U G V$ platform. Another very practical and elegant solution of basic controls is a placement of it on the tactical grip of front hand guard of operator's rifle. This handy control combined with the mentioned rugged tablet gives the riflemanoperator a chance to actuate UGV and scan perimeter almost simultaneously, even to shoot in emergency. All other necessary elements of this teleoperation system, such as transmitter and receiver, batteries, etc. would be distributed onto a tactical/ballistic vest or rucksack and operator could even customize this solution on its own. Then, the semi-autonomous operation delegated by a human could look like as follows:

after activation of UGV, an operator will set up the position of the platform towards his section (that's why UGV has to know the exact position of teammates, eventually other sections and their UGVs, see the Identification IFF part). After that, a UGV continues and moves independently, searches optimal waypoints keeping the given position-task towards unit. The platform needs to run also in the area of strong jamming and GPS signal denial. A list of possible delegation orders for UGV, given by simple symbols on tablet screen, could be seen in Tab. 2.

Tab. 1 Unmanned Systems Integrated Roadmap FY2011-2036 [14]

\begin{tabular}{|l|l|l|}
\hline LEVEL & \multicolumn{1}{|c|}{ NAME } & \multicolumn{1}{c|}{ DESCRIPTION } \\
\hline 1 & Human operated & $\begin{array}{l}\text { A human operator makes all decisions. The system has no } \\
\text { autonomous control of its environment although it may have } \\
\text { information-only responses to sensed data. }\end{array}$ \\
\hline 2 & Human delegated & $\begin{array}{l}\text { The vehicle can perform many functions independently of } \\
\text { human control when delegated to do so. This level encom- } \\
\text { passes automatic controls, engine controls, and other low-level } \\
\text { automation that must be activated or deactivated by human } \\
\text { input and must act in mutual exclusion of human operation. }\end{array}$ \\
\hline 3 & Human supervised & $\begin{array}{l}\text { The system can perform a wide variety of activities when } \\
\text { given top-level permissions or direction by a human. Both the } \\
\text { human and the system can initiate behaviours based on sensed } \\
\text { data, but the system can do so only if within the scope of its } \\
\text { currently directed tasks. }\end{array}$ \\
\hline 4 & Fully autonomous & $\begin{array}{l}\text { The system receives goals from humans and translates them } \\
\text { into tasks to be performed without human interaction. A } \\
\text { human could still enter the loop in an emergency or change the } \\
\text { goals, although in practice there may be significant time delays } \\
\text { before human intervention occurs. }\end{array}$ \\
\hline
\end{tabular}

It is just an example of order sequels; each army could use their own military tongue and create orders for their UGV platforms. Again, it is important to realize that these short orders have to be inputted into the system by some sort of graphical icons or the like and each symbol needs to have an exactly limited and defined value.

We have finally opened a Pandora's Box for armed UGVs by completing these lines - autonomous life-fire on living beings. But to be honest, it is more or less certain, that to grasp maximally all the advantages of automated platforms - robots unmanned vehicles, we have to go this way. Automatic fire support using AI assets target recognition, fire on the most effective part of a target set in memory bank, automatic fire assessment, progressive point-of-aim change et cetera, will take part in it. 
Surely, we still need a human to be there, we could not go along this path without delegated tasks from human operator; he has to define fire sectors, arming of weapons and check the safety etc., but the direct fire alone has to be independent. We need to grasp in this point the most powerful advantage of UGV robots against our enemy the multiple-fast reaction time of machines! Just one example for all - a sniper threat in urban area could be solved with the autonomous fire-response of the UGV (remember automatic defence systems of naval platforms).

Tab. 2 Example of order sequels for UGV system

\begin{tabular}{|c|c|c|c|c|}
\hline ORDER & ASSET/POSITION & $\begin{array}{c}\text { SPACE TOL- } \\
\text { ERANCE } \\
\end{array}$ & $\begin{array}{c}\text { FOLLOW-UP } \\
\text { ORDER }\end{array}$ & $\begin{array}{c}\text { FILTER- } \\
\text { SPECIFICATION } \\
\end{array}$ \\
\hline ESCORT & $\begin{array}{c}\text { team Alfa, Bravo at } \\
\text { Azimuth } 360^{\circ}\end{array}$ & up to $100 \mathrm{~m}$ & Reconnaissance & $\begin{array}{c}\text { Sector FRONT } \\
\left(\mathbf{1 8 0}^{\circ}\right) !\end{array}$ \\
\hline ESCORT & $\begin{array}{l}\text { team Alfa at } \\
\text { Azimuth 90 } \\
\end{array}$ & up to $20 \mathrm{~m}$ & Surveillance & $\begin{array}{c}\text { Sector RIGHT } \\
\left(\mathbf{1 2 0}^{\circ}\right) !\end{array}$ \\
\hline ESCORT & $\begin{array}{c}\text { team Alfa at } \\
\text { Azimuth } \mathbf{2 7 0}^{\circ}\end{array}$ & up to $20 \mathrm{~m}$ & Surveillance & $\begin{array}{c}\text { Visual with team } \\
\text { Bravo! }\end{array}$ \\
\hline ESCORT & $\begin{array}{l}\text { team Bravo at } \\
\text { Azimuth } \mathbf{1 8 0}^{\circ}\end{array}$ & up to $10 \mathrm{~m}$ & Transport only & $\begin{array}{c}\text { Sector BACK } \\
\left(\mathbf{1 8 0}^{\circ}\right) !\end{array}$ \\
\hline PATROL & $\begin{array}{l}\text { team Alfa, Bravo at } \\
\text { Azimuth } \mathbf{3 6 0}^{\circ}\end{array}$ & Route + $5 \mathrm{~m}$ & $\begin{array}{l}\text { Reconnaissance } \\
\text { and Surveillance }\end{array}$ & $\begin{array}{c}\text { Waypoints set by } \\
\mathrm{CO}\left(\mathbf{3 6 0}^{\circ}\right) !\end{array}$ \\
\hline CQB & $\begin{array}{l}\text { team Bravo at } \\
\text { Azimuth } \mathbf{3 6 0}^{\circ}\end{array}$ & up to $5 \mathrm{~m}$ & $\begin{array}{l}\text { Reconnaissance } \\
\text { and Fire support }\end{array}$ & $\begin{array}{c}\text { Auto Fire-response } \\
\text { mode on Tango } \\
\left(\mathbf{9 0}^{\circ}\right)\end{array}$ \\
\hline CQB & $\begin{array}{c}\text { team Alfa at } \\
\text { Azimuth } \mathbf{3 6 0}^{\circ}\end{array}$ & close & $\begin{array}{l}\text { Team extraction } \\
\text { and Fire support }\end{array}$ & $\begin{array}{c}\text { Auto Fire-response } \\
\text { mode on Tango } \\
\left(\mathbf{1 8 0}^{\circ}\right)\end{array}$ \\
\hline
\end{tabular}

This chapter briefly outlined possible technical solutions of armed UGV as a platform for direct-support of mechanized infantry platoons, united with some tactical characteristics of it. These lines were intended to work as a simple schematic model and inspiration for members of armed forces and for designers of unmanned platforms. This issue is really wide and it deserves more attention of all military organizations and design companies; the only certainty is that it will evolve dramatically in the next few years.

\section{UGV in Deployment (notional AAR)}

\section{AFTER ACTION REPORT}

From: $\mathrm{CO}$ of $2^{\text {nd }}$ Mechanized Infantry Bn

To: $21^{\text {th }}$ Mechanized Infantry Bde HQs

Subject: After Action Report - Use of armed UGVs, ARKADIA 2025

This After Action Report is prepared IAW UGV Operators of $2^{\text {nd }}$ MI Bn to evaluate the use of armed UGVs.

The following is information regarding the contingency itself:

Deployed Location: South Arkadia, Halab Al Anwar district

Duration of Deployment: 21/07/2025-23/07/2025

General: Halab Al Anwar district has experienced an extensive increase in enemy activity. Allied forces received heavy attacks along supply routes, concentrated mainly in Al Anwar highway area. Combat teams of 21th Mechanized Infantry Bde body were deployed to participate in MOUT operation CLEAR RESIDENCE. 
Weather: Clear, sunny, variable winds, expecting heavy dust atmosphere, temperatures from $35^{\circ} \mathrm{C}$ to $45^{\circ} \mathrm{C}$ in daylight

Terrain: Urban, heavy barricades

Mission: Search and clear operation in Halab Mosque urban area east of Al Anwar highway. Provide sustainable direct fire-support during MOUT. Conduct reconnaissance in AOR, clear buildings, routes, bridges. Sections of $1^{\text {st }}$ and $2^{\text {nd }}$ Coy of $2^{\text {nd }}$ Mechanized Infantry Bn are provided with support UGVs. Use of lethal force is authorized. Use of unmanned autonomous lethal systems is authorized. ETC 23/07/2025.

Task organization: $\mathrm{xxxxx}$

Call signs: $\mathrm{xxxxx}$

Execution: $1^{\text {st }}$ and $2^{\text {nd }}$ Coy of $2^{\text {nd }}$ MI Bn conduct search and clear operation in their AOR, using assigned combat teams from $4^{\text {th }}$ Tank Coy and section's UGVs for direct fire-support. Secure area of Halab Mosque.

Clearing operations started early morning in AOR of each company, using building-to-building procedures; platoons were supported by assigned tanks of $4^{\text {th }}$ Tank Coy, using streets to cover advance. Sections used UGVs for entering buildings and compounds, where it was possible. UGVs were successfully used for reconnaissance tasks in narrow streets and passages, bridges and gates. Due to eminent firepower and small size, UGVs were used for suppressing fire more often as tanks in narrow-spaced streets. UGV operators worked with semi-autonomous mode under the COs line-of-command.

Number of deployed UGVs - 18, thereof 15 received damage due to enemy fire, 2 were critically damaged and 13 UGVs returned into service after repair. 6 UGVs reported fault functions, solved on the spot. 2 UGVs reported battery capacity problems, solved during deployment.

Two significant events occurred regarding the operation:

21/07/2025 0945 hours; two sections of $3^{\text {nd }}$ Platoon of $1^{\text {st }}$ Coy entered heavy crossfire trap well prepared by insurgents. Concrete barricades were used to block the death-end street, flanked with heavy machine gun fire and light mortars. COs unable to use IFVs and tank for cover and support due to limited access and troopers hidden in line of barracks, so they formed single column formation of both UGVs and used them as heavy firepower penetrators in autonomous fire-response mode.

Troops used their IFFs for closing down to UGVs and initiated withdrawal out of trap. No troops were KIA, 6 WIA. 1 UGV was critically damaged, but managed to last position.

22/07/2025 1900 hours; $1^{\text {st }}$ Platoon of $2^{\text {nd }}$ Coy receives sniper fire from multiple high ground positions. Three were hit on open ground. Two snipers localized and neutralized by direct fire support, one stayed in theatre. CO decided to use UGV for entering area and use it for emergency evacuation of two soldiers. Sniper started to fire upon UGV, but managed no significant damage due to small-calibre weapon fire. 1 KIA, 2 WIA.

Operation CLEAR RESIDENCE ended 23/07/2025 successfully. All tasks fulfilled, AORs taken over.

Lessons learned: UGVs were successfully used as direct fire-support mostly in narrow spaced urban areas, unable to enter with heavy vehicles. They showed sufficient resistance against enemy small-arms fire, very fast response times and sufficient ground clearance. Fully autonomous modes were used only exceptionally, probably due to persistent distrust. All 18 deployed UGVs returned to base, overall function errors reach $33 \%$.

Comments: 1. Overall errors rate needs to be dropped down during the deployment; HQ will contact suppliers and R\&D teams. 2. Battery capacity needs to be improved. 3. UGVs resistance against enemy fire needs to be improved $-83 \%$ received various small-arms fire damage. 4 . Confidence for autonomous functions of armed UGVs needs to be increased during enhanced training program and more frequent exercise. 


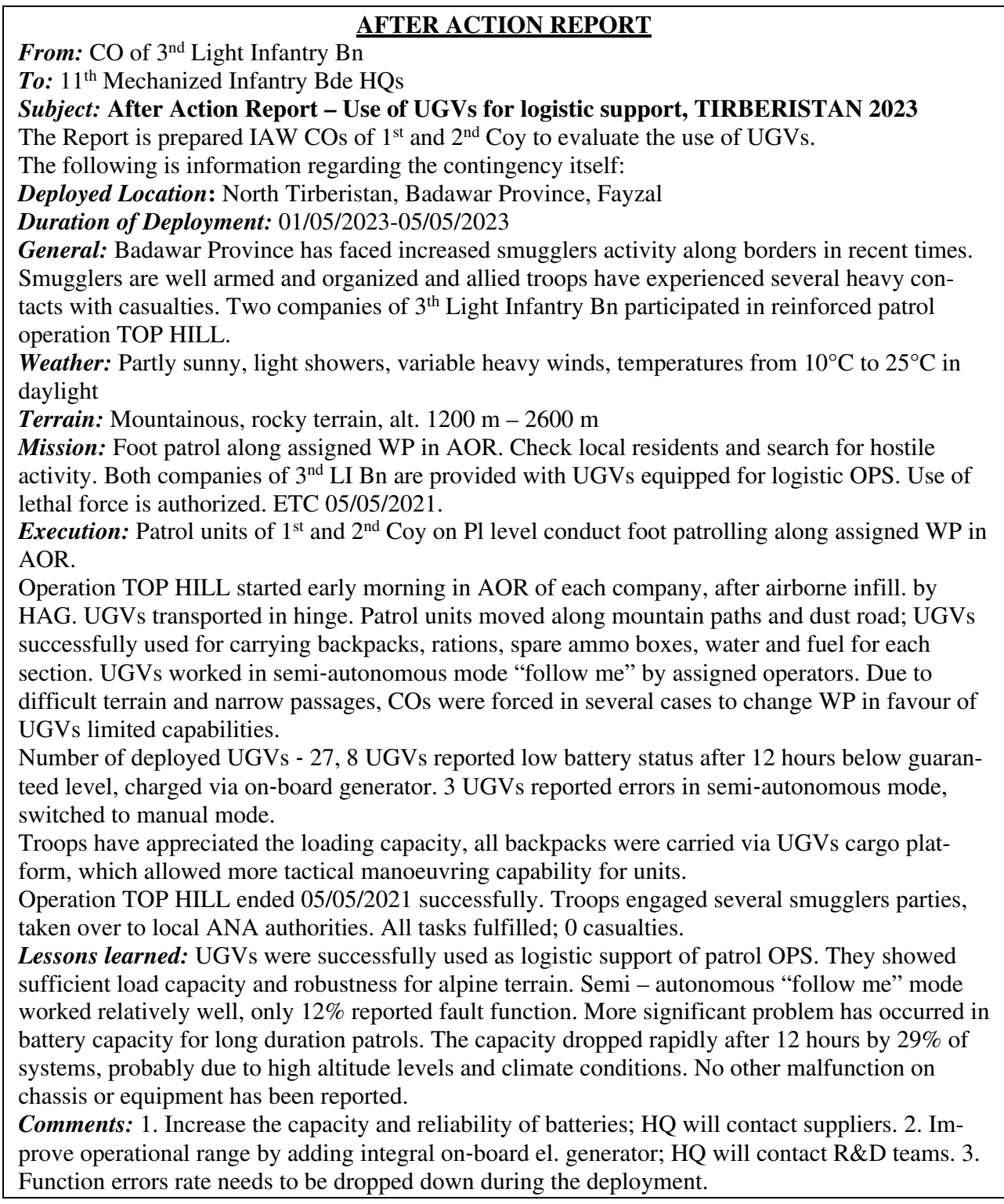

A utopia or next reality? ... We showed two different roles of our UGV platforms in previous AARs using a notional deployment in theoretic future conflicts. Both of these roles could be useful and appreciated by mechanized infantry troops. Although schematic and brief, they show us actual problems which bother today's UGV demonstrators and very likely will do it in near future too, until the technology progress or different conceptions will solve that.

\section{UGV as a Future for Ground Forces}

The important thing is to realize that a progress in warfare is always needed and the load of enormous demands on individual soldier in today's pace of combat operations 
may be solved by using mutual interaction between a man and machine. Joint teams of man-unmanned fighters is the opportunity and the future - whether we want it or not, where a man would be more and more likely a weaker link of the chain hereafter. The doctrine of Armed UGVs use is essential hand by hand of robot's development and deployment; it is required for all new military equipment, it provides reference across units, helps to accomplish combat tasks with minimum casualties and unwanted collateral damage. The unmanned platforms as game-changers and powerful force multipliers will need it considerably. This article shows the way how to think about this asset. Hopefully, all the previous thoughts would serve as an inspiration mainly for commanders of mechanized infantry units on one side, on the other one for designers of UGV platforms. It is important to find a common speech and face the new challenges of next-generation battlefields.

\section{References}

[1] MATEJKA, J. Unmanned Ground Vehicle as a Force Multiplier in Urban Operations (in Slovak). Vojenské rozhledy, 2017, vol. 26, no. 4, p. 119-134. ISSN 1210-3292.

[2] HÉMEZ, R. Eurosatory 2018. Session Use of Automated Systems - Control, Security, Effects. Paris. Personal communication.

[3] SINGER, P.W. Wired for War: The Robotics Revolution and Conflict in the Twenty-first Century. New York: Penguin Press, 2009. 499 p. ISBN 978-0-14311684-4.

[4] Eurosatory 2018: French Company SD4E Unveils Snibot as Hyperprecision Robot for Sniping [on-line]. 2018. [cited 2019-01-23]. Available from: https://www.armyrecognition.com/eurosatory_2018_official_news_online/eurosa try_2018_french_company_sd4e_unveils_snibot_as_hyperprecision_robot_for_s niping.html

[5] OFFICE OF THE CHAIRMAN OF THE JOINT CHIEFS OF STAFF. DOD Dictionary of Military and Associated Terms [on-line]. Washington DC: The Joint Staff, 2019. 382 p. [cited 2019-07-2]. Available from: https://www.jcs.mil/Portals/36/Documents/Doctrine/pubs/dictionary.pdf

[6] ZBOŘIL, I. and CHLUP, V. Before the System of the Soldier for the Czech Army Acquisition (in Czech). Fine Mechanics and Optics, 2009, vol. 4, p. 95-108. ISSN 0447-6441.

[7] ENGLAND, J. BAE Systems Black Knight Tank - Unmanned Combat Vehicle. Military Machine [on-line]. January 2019. [cited 2019-02-21]. Available from: https://militarymachine.com/black-knight-tank

[8] LYSITSIN, P. Prepare to be Terminated - Russia readies First Robot Tank, Shows off Armata at Arms Expo. RIA Novosti [on-line]. September 2015. Available from: https://www.rt.com/news/314963-armata-autonomous-combat-system

[9] NATO. Standardization Agreement (STANAG 4569) Protection Levels for Occupants of Armoured Vehicles. Brussels: NATO, 2014. 8 p.

[10] Electro Optic Systems [on-line]. EOR400S-Mk2 Datasheet. [cited 2019-02-19]. Available from: https://www.eos-aus.com/defence 
[11] Nexter OPTIO X-20 [on-line]. Nexter Systems SA. 2 p. [cited 2019-03-04]. Available from: https://www.nexter-group.fr/sites/default/files/fichiers-catalogue -produit/OPTIO.pdf

[12] Kongsberg PROTECTOR Datasheet [on-line]. Kongsberg Protech Systems. 24 p. [cited 2019-02-15]. Available from: https://www.kongsberg.com/contentassets/ d3a34016b7dc459da15d3a239681e8df/protector_screen_1.pdf

[13] BackTrail - Logistic Trailers for Combat Vehicles [on-line]. Urdan Metal \& Casting Industries Ltd. [cited 2019-04-10]. Available from: http://urdan.co.il/ military/backtrail

[14] Unmanned Systems Integrated Roadmap FY2011-2036. [on-line]. 2011, p. 108. [cited 2019-02-21]. Available from: https://fas.org/irp/program/collect/usroadmap 2011.pdf

[15] SIRAK, M.C. Man on the Loop Air Force Magazine [on-line]. January 2010. [cited 2019-01-11]. Available from: http://www.airforcemag.com/Features/ newtech/Pages/box012510lord.aspx

[16] CORN, G.S. Autonomous Weapon Systems: Managing the Inevitability of Taking the Man Out of the Loop [on-line]. June 2014, 30 p. [cited 2019-02-04]. Available from: https://www.law.upenn.edu/live/files/3894-corn-understandingthe-loop-regulating-the-next

[17] Qinetiq TRC Brochure. [on-line]. Qinetiq North America Inc. [cited 2019-02-04]. Available from: https:/qinetiq-na.com/products/unmanned-systems/trc/tacticalrobot-controller-trc 